\section{Editorial: Produtivismo e Coautoria Cerimonial}

Prezados leitores, quando assumi a editoria da RECADM em meados do ano passado, uma das primeiras ações que tomei foi limitar em três o número de autores por artigo, salvo aqueles artigos que efetivamente necessitassem de mais autores para lidar com grandes complexidades do campo empírico. Como não houve espaço para justificar tal ação em momento anterior, neste editorial eu gostaria de dar algumas boas razões para olhar com mais cuidado a forma como as coautorias de um artigo são definidas, já que há evidências de que uma atitude permissiva em se aceitar indiscriminadamente múltiplas autorias pode aumentar as chances de ocorrer coautoria cerimonial.

Coautoria cerimonial é aquele tipo de coautoria em que o indivíduo é caracterizado como autor, mas cuja contribuição é inexistente ou superficial. Em circunstâncias de coautoria cerimonial, um ou mais autores assumem toda a pompa e cerimônia de um dos desenvolvedores do estudo, gozando dos frutos do reconhecimento pelo ato de publicar uma peça particular de comunicação científica. Todavia, tal manifestação de reconhecimento, de autoridade e de habilidade em se fazer ciência é uma fraude: não há mérito em se fazer ciência quando não há trabalho intelectual ou de investigação.

Há outras denominações para a coautoria cerimonial. Por exemplo, Godoi e Xavier (2012) criticamente e, ao meu ver, mais do que justamente, abordam como ela pode ser evidenciada pela total perda da noção do que é autoria e coautoria. Para os autores, alguns coautores, em analogia ao conceito originário da economia, podem ser denominados de free riders. Para Godoi e Xavier (2012, p. 460), "como pseudoautor, coautor de amigos e dos orientandos, o free rider é autor que não escreve, não colabora, simplesmente usa de sua posição privilegiada para receber os pontos da publicação e benefícios decorrentes. [...] Nos campos da economia, psicologia e ciência política, o free rider, também chamado freeloader (parasita, aproveitador), é um agente econômico que usufrui de um determinado benefício proveniente de um bem, sem que tenha contribuído para a sua obtenção". Baseando-se em Alcadipani (2011), Godoi e Xavier (2012) ainda caracterizam bem outro coautor cerimonial, o burocrata sem consistência ou burocrata de papers. Tal burocrata usa de sua posição como gestor para apropriar-se do trabalho dos demais que, por sua vez, com a sobreposição de cargo burocrático e o excessivo número de publicações, amplia a desigualdade e a concentração de poder na mão de pesquisadores cuja capacidade é questionável.

Internacionalmente, algumas tipificações de coautores cerimoniais (Al-Herz, Haider, Al-Bahhar, \& Sadeq, 2014; McNutt, et al., 2018; Rennie \& Flanagin, 1994) os denominam como guest (convidado), gift (presenteado) ou honorary (honorário). Para McNutt et al. (2018), todas essas tipificações remetem a indivíduos que ganham crédito com a autoria, mesmo não contribuindo de forma substantiva para a pesquisa em que foram adicionados à lista de autores em virtude de sua estatura na organização ou comunidade.
Luciano Rossoni (iD, Editor da RECADM UniGranRio, Brasil Irossoni@gmail.com 
Apesar de ser publicamente reprovável, a coautoria cerimonial é essencialmente eficaz porque é uma prática subterrânea, residindo nas relações íntimas ou de proximidade entre autores. Entre tais práticas, Freitas (2011) cita, por exemplo, que a coautoria cerimonial se manifesta por meio da formação de conluios para publicação, a inclusão de autores totalmente ausentes do trabalho visando à futura reciprocidade, além da frequente inclusão do orientador como coautor em trabalhos dos alunos mesmo que não exista qualquer colaboração. Podemos adicionar mais algumas que, infelizmente, são comuns no cotidiano da produção, como incluir membros da banca, professores que lecionaram a disciplina cujo trabalho final era um artigo, coordenadores de curso e, até por caridade, o nome de professores com baixa capacidade de produção. A lista de coautorias cerimoniais não se esgota aqui, pois há várias formas de manifestação. Infelizmente, creio que muitas outras formas irão surgir, todas fáceis de discernir, mas extremamente difíceis de identificar.

Mas, se há desvios, como então definir autoria? Há discussões recentes sobre como qualificar uma coautoria, como a promovida por McNutt et al. (2018) no Proceedings of the National Academy of Sciences, cuja algumas das implicações foram inclusive reproduzidas por Nassi-Calò (2018) no blog Scielo em Perspectiva. Apesar de tais discussões, boa parte dos editores e periódicos aceitam a definição do International Committee of Medical Journal Editors (ICMJE), cujos critérios são amplamente recomendados, seja na forma como são declarados ou com algumas adaptações. Para a ICMJE (2018), a coautoria baseia-se em quatro critérios:

1. Contribuições substanciais para a concepção ou desenho do trabalho; ou a aquisição, análise ou interpretação de dados para o trabalho; $E$

2. Elaborar o trabalho ou revisá-lo criticamente; $E$

3. Aprovação final da versão a ser publicada; $E$

4. Concordar em prestar contas de todos os aspectos do trabalho, garantindo que as questões relacionadas à precisão ou integridade de qualquer parte do trabalho sejam devidamente investigadas e resolvidas.

Além de tais critérios, a ICMJE (2018) especifica que "um autor deve ser capaz de identificar quais coautores são responsáveis por outras partes específicas do trabalho. Além disso, os autores devem ter confiança na integridade das contribuições de seus coautores." Mas o mais importante é que a ICMJE (2018) é extremamente categórica no que se refere à definição de autoria, em que "todos aqueles designados como autores devem atender a todos os quatro critérios de autoria, e todos que atenderem aos quatro critérios devem ser identificados como autores. Aqueles que não atendem aos quatro critérios devem ser agradecidos".

Se já não fossem bastante claros tais critérios, além de eticamente justos, a ICMJE (2018) dá uma série de exemplos de outras contribuições que não são suficientes para qualificar um indivíduo como autor: aquisição de financiamento; supervisão geral de um grupo de pesquisa ou apoio administrativo geral; assistência de redação, edição técnica, edição de idioma e revisão de textos. 
Perante tais critérios, como os periódicos e editores vêm tentando combater a coautoria cerimonial e outros tipos de anomalias na colaboração acadêmica? Uma alternativa recorrente é exigir que os autores emitam declarações a respeito do papel desempenhado no artigo (McNutt, et al., 2018; Nassi-Calò, 2018). Inclusive há algumas taxonomias para definir cada contribuição, como a CRediT (Contributor Roles Taxonomy), que uniformiza quais são as principais atividades de desenvolvimento de uma pesquisa, cuja contribuição do coautor é incorporada como metadado do artigo. A CRediT estabelece a priori 14 categorias (Nassi-Calò, 2018): conceituação, metodologia, software, validação, análise formal, investigação, recursos, curadoria de dados, escrita - primeira redação, escrita - revisão e edição, visualização, supervisão, administração do projeto e obtenção de financiamento.

Existe a expectativa de que o uso de tais categorias de taxonomia facilite a discussão sobre critérios de coautoria entre os pesquisadores, bem como facilite o estabelecimento de ordem de autoria (McNutt et al., 2018; Nassi-Calò, 2018). No entanto, os desvios na conduta acadêmica no que se refere à coautoria não é motivada por uma ausência de critérios. Isso é um problema essencialmente ético que deve ser enfrentado na prática acadêmica cotidiana, como bem apontaram Vizeu, Macadar e Graeml (2016). Tanto que o uso de tais declarações de contribuição não surtiria qualquer efeito se de antemão temos uma postura antiética acerca da definição de coautoria. Pois, se indivíduos que não contribuem para uma pesquisa em particular aceitam ser publicamente nominados como autores, por que também não simulariam papeis fictícios em tais declarações? Por isso, neste atual estágio, a RECADM optou por limitar o número de autores. Isso porque impera em muitas áreas da ciência, e na administração em particular, uma deontologia produtivista, que já se incorporou no cotidiano da produção acadêmica como episteme.

Evidências dessa deontologia produtivista podem ser vistas na Figura 1. Nela, eu utilizo 30 anos de publicações dos periódicos nacionais em administração indexados no Spell para expor três padrões que foram construídos a partir do trabalho de Braun, Glänzel e Schubert (2001). Um deles remete à Cooperação, que é medida por meio do número médio de autorias por artigo. Os dados dão a entender que o estabelecimento do Qualis em 1998 demarcou uma guinada no padrão de coautoria dos artigos, cuja média era de 1,49 autores por artigo, chegando a 2,16 autores em 2006, ano em que foi estabelecido o Novo Qualis, batendo o teto de 2,86 autores por artigo em 2017. Isso implica que, em quase 20 anos de Qualis, apesar de nunca ter havido uma pressão por aumento de coautoria, incluímos quase um autor e meio em cada artigo. A pergunta fundamental é, para quê? Na minha opinião, boa parte dessa massa de autorias foi incorporada cerimonialmente, fomentando em parte 0 produtivismo da área, cujas altas taxas são concentradas num número não tão grande de pesquisadores, já que mecanismos de escolha preferencial operam subjacente ao campo (Rossoni, Guarido Filho, \& Machado-da-Silva, 2010). 


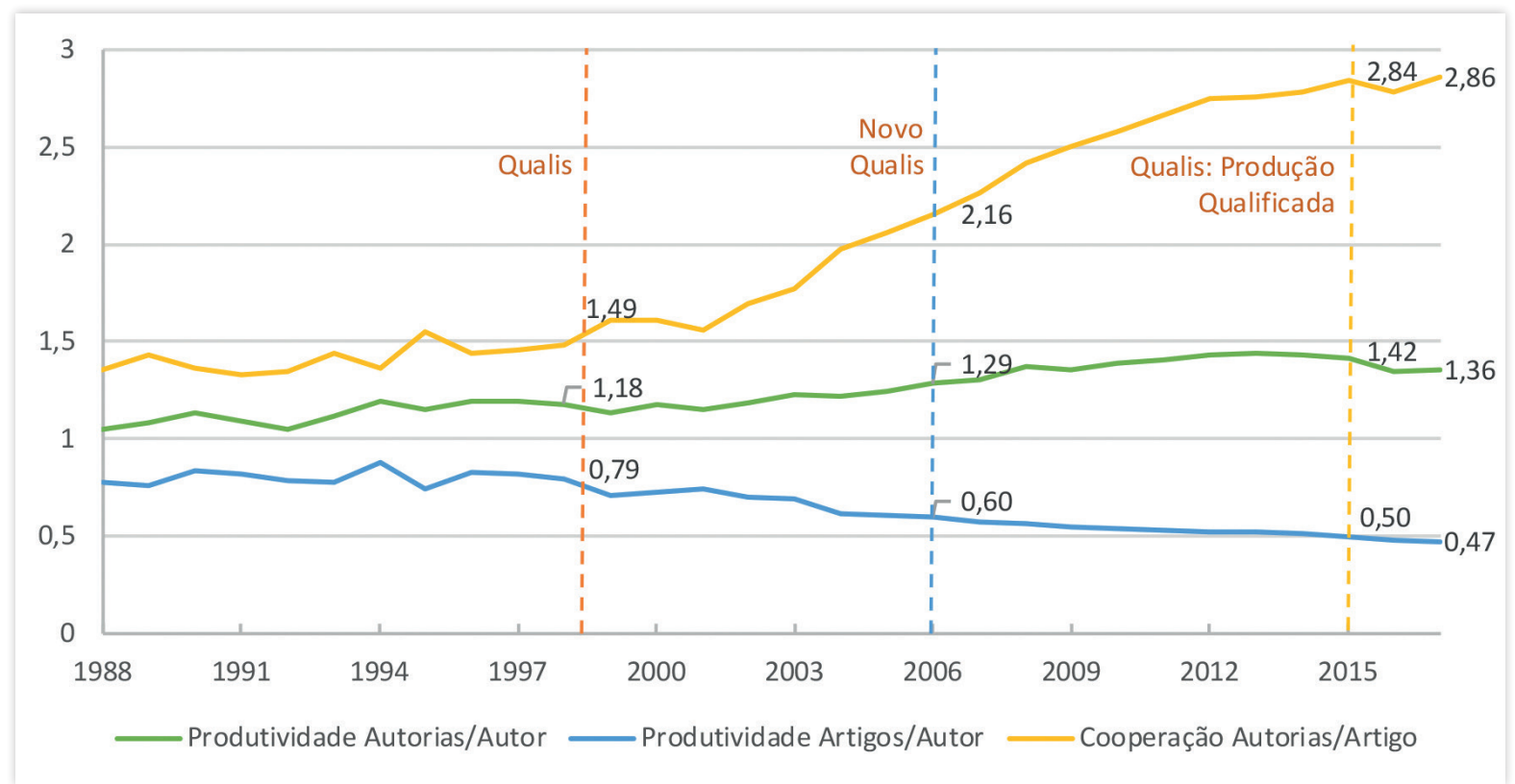

Figura 1. Produtividade e Cooperação no Spell (1988-2017).

Além da cooperação, outro padrão que se pode observar é o de Produtividade ponderando o número de Autorias por Autor. Apesar de haver um crescimento pós Qualis, nota-se que ele não foi tão acentuado como o da Cooperação. Em 1998 havia em média 1,18 autorias por autor, passando para 1,29 em 2006 e culminando em 1,42 em 2015. E hoje, dois anos após a mudança de avaliação dando maior peso à produção qualificada, temos um quadro de queda na produtividade, já que em 2017 houve 1,36 autorias por autor. O fato é que a cooperação não converteu sua maior produtividade em termos de autoria nas mesmas proporções porque, como apontei, há uma forte estratificação na área em que autores pontuais usam dos onetimers (Braun et al., 2001), normalmente mestrandos, para produzir. Mas, na média, não são todos os autores que conseguem angariar mais autorias dessa forma. Pelo contrário, essa é uma minoria, o que reflete num aumento não tão significativo da produtividade.

O outro indicador de Produtividade, pautado no número de Artigos Produzidos por Autor, foi desenvolvido por Braun, Glänzel e Schubert (2001) tendo como base o trabalho de Ajiferuke, Burell e Tague (1998). Tal indicador reflete o grau de divisão do trabalho acadêmico, sendo a real medida do esforço individual de um autor em relação ao seu envolvimento com os artigos que produz. Como poder ser visto na Figura 1, a produtividade, que fora bem estável até 1998, caiu de 0,79 artigos por autor em 1998 para $0,60 \mathrm{em} 2006$. A produtividade ainda regrediu para 0,5 artigos por autor em 2015, caindo no fosso de 0,47 artigos por autor em 2017.

Logo, como se fosse uma ironia dos Deuses da ciência, os dados apontam que toda a lógica e esforço produtivista, ao invés de aumentar a produtividade da área, fez com que ela desabasse. Nos transformamos num campo que explora alunos, que adultera a autenticidade da autoria, que premia os exageradamente produtivos e pune aqueles que produzem de forma mais reflexiva para, no fim, sermos menos produtivos. Creio que 
esse seja um ótimo exemplo de uma péssima prática individualista que, por oportunismo, destrói com as vantagens coletivas do se fazer ciência. E, como advogo aqui, diante da capacidade limitada de trabalho dos humanos pesquisadores, o produtivismo se alicerçou na exploração da mão de obra alheia por meio de coautorias cerimoniais. Por essa razão, mesmo que falha, venho justificar a ação da RECADM em limitar as autorias, pois mesmo não garantindo que não ocorra coautoria cerimonial, ela será menos provável e mais difícil.

\section{Nesta Edição}

Nesta segunda edição de 2018, nós convidamos a todos os leitores a visitar a nova página da RECADM (http://www.periodicosibepes.org.br/ recadm). Como poderão ver, aperfeiçoamos o layout da página, deixando-a mais funcional, ressaltando as informações mais relevantes do periódico. Além disso, temos mais duas novidades nas páginas dos artigos: 1) o Crossmark, que já tinha sido incorporado nos documentos, agora também está acoplado à página dos artigos, facilitando ainda mais a checagem da consistência e da atualidade da informação das publicações; 2) a incorporação do Citedby do Crossref, que permite visualizar quais documentos citaram os artigos publicados na RECADM. Vale ressaltar que essas mudanças e outras que ainda estão por vir, têm como objetivo melhorar a experiência de uso de autores, leitores e revisores, que tanto contribuem para que a RECADM seja um periódico dinâmico e atual.

Os artigos desta edição contemplam temáticas variadas, que vão desde a temas pontualmente atuais como a evasão de estudantes em cursos a distância, empoderamento na recuperação de serviço e empreendedorismo social, até a temas com maior tradição em seus campos, como desenvolvimento de escalas psicométricas, impactos da sustentabilidade no consumo e efeitos da imagem do produto na qualidade percebida. Apesar de tal variabilidade, a grande maioria se utiliza de métodos quantitativos de investigação, o que, aparentemente, vêm sendo uma tendência na área de administração brasileira e recorrente nas publicações da RECADM. Há mais de dez anos, alguns levantamentos que fiz sobre o perfil metodológico das publicações apontavam que a maioria das áreas temáticas em Administração tinham um viés qualitativo. Hoje, é bem provável que seja o contrário. Cabe ressaltar que, apesar dos avanços que o uso de métodos mais robustos de análise propicia para o rigor e para a confiabilidade das investigações, causa espanto o uso indiscriminado de alguns métodos, ao ponto de, em alguns casos, se distorcer o fenômeno investigado para atender a critérios de uma técnica específica sem ao menos ponderar alternativas. Talvez o uso de modelagem de equações estruturais seja o caso mais emblemático, em que raramente são considerados outros modelos, muitas vezes muito mais adequados para o tipo de fenômeno investigado. Entretanto, independentemente desses problemas com o uso de métodos quantitativos na área, nesta edição temos bons exemplos de como métodos de investigação quantitativa, e também qualitativa, podem ser utilizados de forma adequada para responder questões de pesquisa relevantes e instigantes. 
O primeiro artigo, "Persistência e Evasão na Educação a Distância: Examinando Fatores Explicativos", de autoria de Ana Cristina Lott, Angilberto Sabino de Freitas, Jorge Brantes Ferreira e Yuri Lott, testa um modelo teórico para investigar fatores que influenciam a persistência e evasão de alunos em cursos de graduação a distância. Os resultados revelam que o suporte à aprendizagem, a autodisciplina e o incremento na renda aumentam as chances dos alunos permaneceram no curso, já o aumento no número de filhos e a escolha por alguns cursos específicos facilitam a evasão.

No segundo artigo, "Contribuições do Empreendedorismo Social para o Aumento da Participação das Mulheres no Mercado de Trabalho", as autoras Vania de Fátima Barros Estivalete, Tais de Andrade e Vivian Flores Costa realizam uma pesquisa de caráter descritivo e de natureza qualitativa, cujo objetivo é analisar a perspectiva de coordenadoras e integrantes de empreendimentos coletivos inseridos em uma incubadora social brasileira. No que tange à inclusão feminina no mercado de trabalho, os resultados refletiram algumas dificuldades enfrentadas por mulheres participantes dos empreendimentos, destacando a falta de oportunidades de qualificação e participação no mercado formal. Para muitas entrevistadas, participar desses empreendimentos representou a primeira oportunidade de inclusão no mundo do trabalho.

O terceiro artigo, de autoria de Luís Anunciação, Sérgio Roberto da Silva, Fernando de Almeida Santos e J. Landeira-Fernandez, intitulado "Redução da Escala Tendência Empreendedora Geral (TEG-FIT) a partir do Coeficiente de Validade de Conteúdo (CVC) e Teoria da Resposta ao Item (TRI)" se utiliza de conhecimentos da psicometria para desenvolver uma versão reduzida da escala TEG, mas preservando suas características essenciais. Metodologicamente, duas etapas foram empregadas: inicialmente, especialistas em empreendedorismo (juízes) avaliaram o conteúdo e a facilidade de entendimento dos itens e, em seguida, as respostas foram modeladas por um modelo de 2 Parâmetros Logísticos (2PL) da Teoria de Resposta ao Item (TRI), utilizando os dados de 147 participantes. A versão final consistiu em uma escala suficientemente unidimensional, que mede o empreendedorismo por 19 itens dicotômicos e que foi chamada de TEG-FIT.

No quarto artigo, intitulado "Empoderamento na Recuperação do Serviço: Implicações na Percepção de Equidade e Lealdade do Cliente", os autores Wandick Leão e Juliana Bonomi Santos investigam o empoderamento na recuperação do serviço por meio de um levantamento com clientes em serviços bancários. Os resultados mostram que o empoderamento traz maior equidade ao processo de recuperação de serviço e promove a lealdade dos clientes.

O quinto artigo, "Influência do Conhecimento sobre Sustentabilidade nas Atitudes, Comportamentos e Consumo de Estudantes de Administração", de coautoria de Ana Cristina de Faria, Luciano Sant'Anna da Silva, Dirceu da Silva e Marco Antônio Figueiredo Milani Filho, busca avaliar o conhecimento sobre sustentabilidade dos alunos do curso de administração de empresas e a influência deste em suas atitudes, comportamentos e consumos sustentáveis. O estudo aponta que há influência do conhecimento sobre sustentabilidade nas atitudes, no comportamento e no consumo dos alunos. Contudo, não se confirmou a influência da atitude no consumo. 
O último e sexto artigo, "A Configuração da Imagem do Produto na Percepção dos Compradores de Apartamentos", de autoria de Deonir De Toni, Maurício Caetano Nedeff, Gabriel Sperandio Milan e Ana Paula Graciola, busca verificar como é configurada a imagem do produto apartamento, na perspectiva dos moradores e os impactos desta imagem nas suas intenções de compra. Os resultados apontaram que o apartamento pode ser definido como uma moradia que proporciona segurança, praticidade e bem-estar, atrelado à privacidade e à coletividade, em que os significados simbólicos e sensoriais não impactaram nas intenções de compra, ao passo que os significados emocionais e funcionais são determinantes da intenção de compra.

Finalizando, gostaria de agradecer o empenho dos autores em atender às solicitações de aprimoramento que ocorreram em todo o processo editorial e, especialmente, aos revisores, que voluntariamente dedicam horas de trabalho e seu valoroso conhecimento para tornar a RECADM cada vez melhor. Um periódico de qualidade é um empreendimento de muitas mãos, em que a divisão do trabalho de revisão e editoração, quase todo realizado virtualmente, só é possível devido a presença de pesquisadores atuantes e revisores dedicados.

Uma excelente leitura,

Luciano Rossoni

Editor da RECADM 


\section{Referências}

Ajiferuke, I., Burell, Q., \& Tague, J. (1988). Collaborative coefficient: A single measure of the degree of collaboration in research. Scientometrics, 14(5-6), 421-433.

Al-Herz, W., Haider, H., Al-Bahhar, M., \& Sadeq, A. (2014). Honorary authorship in biomedical journals: how common is it and why does it exist? Journal of Medical Ethics, 40(5), 346-348.

Alcadipani, R. (2011). Resistir ao produtivismo: uma ode à perturbação acadêmica. Cadernos EBAPE.BR, 9(4), 1174-1178.

Braun, T., Glänzel, W., \& Schubert, A. (2001). Publication and cooperation patterns of the authors of neuroscience journals. Scientometrics, 50(3), 499-510.

Freitas, M. E. (2011). O pesquisador hoje: entre o artesanato intelectual e a produção em série. Cadernos EBAPE.BR, 9(4), 1158-1163.

Godoi, C. K., \& Xavier, W. G. (2012). Productivism and its anomalies. Cadernos EBAPE.BR, 10(2), 456-465.

ICMJE (2018). Defining the Role of Authors and Contributors, International Committee of Medical Journal Editors. Acesso em 03 de Maio de 2018. Disponível em: http:// www.icmje.org/recommendations/browse/roles-and-responsibilities/defining-therole-of-authors-and-contributors.html

McNutt, M. K., et al. (2018). Transparency in authors' contributions and responsibilities to promote integrity in scientific publication. Proceedings of the National Academy of Sciences, 115(11), 2557-2560.

Nassi-Calò, L. (2018). Critérios de autoria preservam a integridade na comunicação científica, SciELO em Perspectiva. Acesso em 03 de Maio de 2018. Disponível em: $\quad$ https://blog.scielo.org/blog/2018/03/14/criterios-de-autoria-preservam-aintegridade-na-comunicacao-cientifica/

Rennie, D., \& Flanagin, A. (1994). Authorship! authorship! Guests, ghosts, grafters, and the two-sided coin. Jama, 271(6), 469-471.

Rossoni, L., Guarido Filho, E. R., \& Machado-da-Silva, C. L. (2010). A questão da agência em redes acadêmicas de pesquisa: centralidade, produtividade e escolha preferencial. Redes. Revista hispana para el análisis de redes sociales, 19, 95-121.

Vizeu, F., Macadar, M. A., \& Graeml, A. R. (2016). Produtivismo acadêmico baseado em uma perspectiva habermasiana. Cadernos EBAPE.BR, 14(4), 984-1000. 